\title{
O conceito de Identidade/Subjetividade e o processo de adoção de crianças indígenas no Mato Grosso do Sul
}

The Identity/Subjectivity concept and the adoption process of indigenous children in Mato Grosso do Sul

\author{
Sílvia Mara de Melo ${ }^{1}$ \\ Universidade Federal da Grande Dourados - UFGD \\ silviamelo@ufgd.edu.br
}

\begin{abstract}
RESUMO: A partir de um olhar discursivo, propomos selecionar notícias veiculadas na mídia relacionadas ao processo de adoção de crianças indígenas na cidade de Dourados, região do Mato Grosso do Sul. Devido às contradições e polêmica envolvendo esse tema, propomos refletir acerca dos sentidos de Identidade e Subjetivação tendo como aporte teórico para sustentar nossa análise os dizeres de autores que se filiam tanto à tendência discursiva de base Foucaultiana quanto Pecheutiana. Dialogamos também com os autores dos estudos culturais, tais como Stuart Hall (2006) e Katryn Woodward (2014). Nossa hipótese é de que os sentidos de Identidade cultural que aparecem em enunciados jornalísticos, os quais foram reportados tanto da FUNAI quanto da Vara da Infância e Juventude, não se sustentam, diante da problemática envolvendo os sujeitos indígenas "sobreviventes" na região do Mato Grosso do Sul. Nossas reflexões apontam para um entendimento de que o processo de Identidade/Subjetividade se marca pela cristalização de estereótipos e preconceitos.
\end{abstract}

Palavras-chave: Identidade Cultural; Povos indígenas; Discurso.

ABSTRACT: From a discursive outlook, we proposed to exam the media news related to the adoption process of indigenous children in Mato Grosso do Sul region. Due to contradictions and controversies involving this theme we propose to reflect on the senses of Identity and subjectivity while having as a theoretical contribution the sayings of the authors who are affiliated to the discursive trend of Foucault' base as well as Pecheut's. We also applied authors of the Cultural Studies, such as Stuar Hall (2006) and Katryn Woodward (2014). Our hypothesis is that the sense of the Cultural Identity on the journalistic statements, which were taken of statements such as FUNAI as of the Court of Childhood and Youth do not support themselves in the face of the problematic involving the "surviving" indigenous subjects in the Mato Grosso do Sul region. Our thinking indicate an understanding that Identity/Subjectivity process are consolidated through crystallization of stereotypes and prejudice.

Keywords: Cultural Identity; Indigenous; Discourse.

\footnotetext{
${ }^{1}$ Possui graduação em Letras - Português/Inglês pela Universidade Estadual de Maringá (1998), mestrado em Letras (2004) e doutorado em Linguística e Filologia da Língua Portuguesa (2009), ambos pela Universidade Estadual Júlio de Mesquita Filho, Campus de Araraquara (2009). Atualmente é professora adjunta na Universidade Federal da Grande Dourados (UFGD), Faculdade de Comunicação Artes e Letras (FACALE). Tem experiência na área de Linguística, atuando principalmente nas áreas: análise do discurso, leitura e produção de textos, linguística. Integra o quadro de docentes do Programa de Pós-graduação em Letras da UFGD, área de Linguística e Transculturalidade; Estudos de Linguagem e Discurso.
} 


\section{Introdução}

Este artigo procura abordar questões relacionadas aos indígenas sobreviventes na região de Dourados, cidade localizada no Estado de Mato Grosso do Sul, e a análise faz parte do projeto de pesquisa intitulado "As representações midiáticas do sujeito indígena sobrevivente no Estado do MS", pesquisa que se encontra vinculada à Universidade Federal da Grande Dourados. Nosso material de análise serão duas matérias jornalísticas publicadas no jornal O Progresso nos dias 27 de dezembro de 2017 e 14 de março de 2018, respectivamente. As notícias publicadas num espaço de 3 meses apresentam o assunto “adoção de crianças indígenas". Elas foram selecionadas para compor esta análise porque apresentam um tema bastante polêmico e recorrente e de suma importância para a sociedade, especialmente em regiões em que a presença da população indígena é notória. Pretendemos eleger como aporte teórico tanto conceitos de autores que escrevem a partir da perspectiva discursiva quanto daqueles que se posicionam a partir dos estudos culturais. Essa interface teórica é de suma relevância nessa abordagem porque a noção de Identidade é bastante eficaz na perspectiva dos estudos culturais.

Antes mesmo de examinar tais matérias jornalísticas, buscamos compreender que na cidade de Dourados e no seu entorno há várias etnias indígenas e algumas delas vivem em situação de vulnerabilidade. Não pretendemos correr o risco de generalizações, tendo em vista que há diferenças culturais entre as etnias, tais como a etnia Terena e a Guarani, por exemplo. Como não é objetivo estudar as especificidades de cada uma, nosso objeto de análise se restringirá apenas às matérias publicadas no jornal O Progresso no que diz respeito aos povos indígenas localizados nessa região do MS. Sabemos que o modo de vida das diferentes etnias na cidade de Dourados é bastante complexo. Sem pretender exaurir tal complexidade, aqui faremos recortes de questões problemáticas a partir das notícias do jornal local da cidade. $\mathrm{O}$ jornal local comumente apresenta matérias envolvendo a população indígena; notícias de estupro, uso de drogas e bebidas alcoólicas, violência contra criança e mulheres são rotineiramente veiculadas em jornais impressos e on-line na mídia regional.

É diante deste cenário que essas duas matérias foram selecionadas para serem analisadas neste momento de nossa pesquisa. A escolha dessas duas notícias se justifica porque há contradições no entendimento do processo de adoção de crianças indígenas e são essas contradições que pretendemos identificar discursivamente neste artigo. A polêmica ocorre porque o sujeito indígena é representado por duas instituições legítimas: A Vara da 
Infância e Juventude e a Fundação Nacional do índio - FUNAI. Vejamos brevemente a função dessas duas instituições de onde os discursos emanam.

\section{Enunciados Institucionalizados e a "proteção" dos povos indígenas: a FUNAI}

As varas da infância e da juventude recebem processos envolvendo adoção, casos de infração, vagas em creche entre outras demandas no que diz respeito a infância e juventude. Entende-se que a vara da infância e juventude seja o órgão competente para realizar ações no âmbito dos interesses de crianças e adolescentes de acordo com o Estatuto da Criança e do Adolescente.

De acordo com informações do site <www.funai.gov.br>, pode-se depreender que a Fundação Nacional do Índio - FUNAI foi criada em dezembro de 1967 vinculada ao ministério da justiça e se coloca como coordenadora dos assuntos indigenistas do governo federal brasileiro, tendo como missão proteger e promover os direitos dos indígenas no país. Além de monitorar e fiscalizar as terras indígenas, é seu papel também atuar na proteção dos povos isolados, bem como articular ações na garantia dos processos sociais e de cidadania aos povos indígenas, monitorando políticas voltadas à educação dos povos originários. A atuação da FUNAI está orientada por diversos princípios, dentre eles estão: a valorização dos costumes, a língua, crenças e tradições dos povos indígenas.

O serviço de proteção dos povos originários foi criado há 100 anos e atendia pela sigla SPILTN, Serviço de Proteção ao Índio e Localização de Trabalhadores Nacionais, que fora extinta, mas a FUNAI tem suas origens nessa organização.

Criado em 1910, o Serviço de Proteção ao Índio (SPI), de acordo com Orlandi (2008), teve como finalidade proteger os indígenas e implementar uma estratégia de ocupação territorial no país. A criação do SPI foi uma tentativa de modificar o quadro que vinha se delineando desde o final do século XIX. No século XX, apesar dos acontecimentos históricos relevantes, pós-período colonial, não houve grandes avanços no modo de encarar a presença dos indígenas no país. A política dos missionários em convertê-los pela catequese não trouxe benefícios nem foi capaz de defender seus territórios contra invasores, nem impedir seu extermínio, seja em decorrência das doenças que os contagiavam, seja promovido por matadores profissionais que eram contratados para abrir caminho à imigração e à especulação de terras. 
Vale mencionar aqui o modo como Eni P. Orlandi, em sua pesquisa acerca das questões indígenas trazidas à tona em seu livro Terra à Vista, compreende o SPI. Para Orlandi (2008, p. 71), o SPI foi "necessário para organizar a tomada da terra e controlar a resistência indígena". Para ela, "o SPI foi um serviço de controle do índio e de proteção ao branco, ou melhor, de alguns brancos". Na primeira década do século XX, com o avanço das estradas de ferro na região noroeste do Brasil, conforme os não indígenas avançavam em terras indígenas, ocorria a resistência, havendo um embate entre indígenas e não indígenas. De acordo com Orlandi, em 1908, “o índio tinha se tornado um grave problema nacional, ou seja, o índio (e sua resistência) ficaram mais visíveis. Era preciso apagar essa visibilidade" (2008, p. 71).

Para administrar os conflitos entre povos indígenas e não indígenas, foi estigmatizado o sujeito indígena em duas categorias: selvagem e civilizado. Denomina-se selvagem aquele que resiste à invasão e, portanto, legitima-se o processo de extinção pela violência por parte do homem branco. É nesse contexto, que, segundo Orlandi (2008), o SPI fora gestado. Para ela, o SPI, do ponto de vista do apagamento, tinha "como função gerenciar conflitos entre índios e brancos, dando ao branco o poder de controle tanto em sua dimensão efetiva quanto retórica, ou seja, a função de dar sentidos aos conflitos, ao contato" (ORLANDI, 2008, p. 73).

\section{A polêmica em casos de adoção de crianças indígenas no MS}

Os enunciados foram extraídos nos anos de 2017 e 2018 do jornal impresso $O$ Progresso. Estamos denominando A1, A2, A3, A4, A5 os recortes da matéria publicada em dezembro de 2017; e B1, B2, B3 os recortes da matéria publicada em março de 2018. A escolha dessas duas matérias nesse espaço de tempo se justifica porque o conteúdo delas refere-se à "adoção de crianças indígenas", tema que abordamos, neste artigo, a partir da problematização da noção de Identidade e Sujeito.

\section{TEXTO A}

JUIZ LIBERA ADOÇÃO DE CRIANÇA INDÍGENA EM CADASTRO NACIONAL (Medida tem a finalidade de garantir que dezenas de crianças tenham a chance de ter uma família. Número de acolhimento no Lar Santa Rita dobra além da capacidade)

(Jornal O Progresso, 27/12/2017 - Valéria Araújo)

A1) "A Vara da Infância e Juventude de Dourados vai liberar crianças indígenas de Dourados para o cadastro nacional de adoção, para ter a chance de serem adotados por famílias não indígenas. De acordo com o juiz Zaloar Murat Martins, a medida é necessária porque essas crianças não estão tendo a opção de 
serem acolhidas por famílias indígenas e por isso estão permanecendo muito tempo nos abrigos, muitas vezes passando toda a infância e juventude nesses locais, sem a chance de viver num lar" [...]

A2) "[...] A maior dificuldade para não-indígenas adotarem indígenas vinha de restrições estipuladas por órgãos como a Fundação Nacional do índio (FUNAI), para evitar que perdessem a identidade cultural ". [...]

A3) "[...] Não nos chegam famillias indigenas interessadas em adotar. Além disso, indígenas relatam medo porque geralmente os pais indigenas que abandonam são os mesmos que ameaçam e tentam raptar as crianças".

A4) "[...] Para se ter uma ideia, nos últimos seis meses o número de crianças acolhidas no Lar Santa Rita dobrou, além da capacidade da unidade [...] do total de 40 crianças acolhidas na unidade, 25 são indígenas. A maioria tem menos de 5 anos, são vítimas de abandono, maus tratos e violência sexual. Os pais são dependentes de álcool e outras drogas".

A5) "Temos que acabar de vez com esse tabu que é de falar em adoção de indigenas".

\section{TEXTO B}

Ação da FUNAI retira crianças indígenas de abrigos de MS - Fundação está mapeando parentes de 50 indiozinhos que estão acolhidos em instituições de Dourados. Também quer família Acolhedora na Reserva.

(Jornal O Progresso, 14/03/2018 - Valéria Araújo)

B1 “[...] A Fundação Nacional do Índio (FUNAI) quer retirada de pelo o menos 50 crianças indígenas que estão espalhadas em instituições acolhedoras de Dourados. Para isso começou a mapear familiares que estão na reserva e que estariam dispostos a adotar. A medida tem a finalidade de impedir a adoção via cadastro nacional por não-índios" $[\ldots]$

B2 "[...] A ideia é manter essas crianças nas aldeias para que não percam sua identidade cultural”.

B3 “[...] Equipe da Funai também constatou um descuido por parte de profissionais que atuam com essas crianças no sentido de verbalizarem impressões preconceituosas acerca dos povos indígenas, principalmente sobre o que é noticiado na imprensa. Também apontam o processo traumático da retirada da criança do convívio familiar para um local totalmente desconhecido, distante e que não fale seu idioma".

A matéria do dia 27 de dezembro de 2017 (Texto A) elenca enunciados advindos da instituição jurídica "Vara da infância e juventude de Dourados", representada pela voz do juiz Zaloar Murat Martins, a quem compete tomar decisões quando o assunto é infância e juventude. O juiz ocupa um lugar na sociedade que lhe permite "liberar crianças indígenas de Dourados para o cadastro nacional de adoção", mesmo que tal decisão esbarre em polêmica e contradições com outros setores da sociedade. Segundo o juiz, as crianças indígenas estão ficando muito tempo nos abrigos e, por essa razão, o nome delas foi incluído no cadastro nacional juntamente com o nome de outras crianças, independentemente de etnia. 
Chama nossa atenção um dos motivos elencados nessa matéria em que a FUNAI interfere e impede que crianças indígenas sejam adotadas por famílias não-indígenas. Teme a FUNAI que as crianças percam a "identidade cultural". Nosso objetivo é trazer à tona, nesse momento, uma reflexão quanto ao sentido de Identidade. No texto B (em que faz ecoar o enunciado da FUNAI), surge o seguinte enunciado: "a ideia é manter essas crianças nas aldeias para que não percam sua identidade cultural”.

O sentido de Sujeito e de Identidade serão tomados aqui a fim de que possamos compreender a justificativa da FUNAI quanto a seu posicionamento em relação à adoção de crianças indígenas em contradição ao que propõe a vara da infância e juventude.

Para Orlandi (2002, p. 53),

ao dizer, o sujeito significa em condições determinadas, impelido, de um lado, pela língua e, de outro, pelo mundo, pela sua experiência, por fatos que reclamam sentidos, e também por sua memória discursiva, por um saber/poder/dever dizer, em que fatos fazem sentido por se inscreverem em formações discursivas que representam no discurso as injunções ideológicas.

Compreendemos que é a partir da posição de instituição legítima que membros da FUNAI deliberam sobre assuntos concernentes aos indígenas. A esse órgão foi dado o poder pelo Estado de tomar decisões quanto aos interesses indígenas. É a partir desse lugar legitimado e endossado pelo Estado que a Funai contradiz a vontade jurídica no que concerne ao assunto "adoção de crianças indígenas".

Ao pensar uma criança indígena nas condições sócio-históricas em que está inserida na cidade de Dourados-MS, diríamos que manter uma Identidade cultural é contraditório e não corresponde ao modo de vida deste sujeito. De acordo com a análise do discurso, o sujeito é clivado, heterogêneo e, nesse sentido, podemos afirmar que não existe uma identidade fixa. $\mathrm{O}$ sujeito indígena que mora na aldeia também frequenta o ambiente escolar, o comércio e alguns conseguem ingressar em uma Universidade. O sujeito que não é indígena, mas branco, pardo ou negro, que se encontra nos lares para adoção também não é uno, homogêneo e não tem uma identidade fixa.

O sujeito, de acordo com Pêcheux (1997), é afetado pelas condições sócio-históricas e ideológicas nas quais está inserido. No enunciado A4, "os pais são dependentes de álcool e outras drogas". Ao se constatar que certos pais de crianças que se encontram para adoção são usuários de drogas ou consumidores de bebida alcoólica, é preciso que resgatemos as condições de produção de tal sequência discursiva. 
Para Orlandi (2002, p. 30), "condições de produção compreendem fundamentalmente os sujeitos e a situação", ela entende que as condições de produção podem ser tanto as circunstâncias da enunciação, bem como o contexto sócio-histórico, ideológico. Compreendemos que ao justificar que crianças indígenas se encontram no lar para adoção porque alguns pais estão em condições de vulnerabilidade, envolvidos com drogas, é lícito compreendermos as condições de produção das drogas na cidade de Dourados tendo em vista que esta é uma cidade fronteiriça com Paraguai e é possível que a entrada de drogas ilícitas seja facilitada à população indígena, embora se deva considerar que o uso de drogas é generalizado e, infelizmente, afeta os sujeitos de maneira indistinta, tanto o branco, quanto o negro, o rico e o pobre.

Os pais que abandonam as crianças no lar para adoção, indígena ou não, tem essa atitude por diversos motivos, induzidos pela pobreza extrema, incapacidade emocional para cuidar de uma criança (pois é comum meninas muito jovens engravidarem), envolvimento com drogas ou álcool etc. É preciso se compreender que as razões que levam um pai ou uma mãe a abandonar uma criança são parecidas. Pensar uma comunidade indígena sem a interferência do mundo neoliberal é desconsiderar as reais condições em que vive o indígena hoje no Brasil. Preservar uma "identidade cultural" é procurar manter um discurso que não se sustenta nas condições reais de existência dos povos originários, pelo menos no que diz respeito à cidade de Dourados.

A situação do sujeito indígena no Estado do Mato Grosso do Sul nos faz dialogar com Stuart Hall no que se refere ao conceito de Identidade. Para Hall (2006), as identidades estão sendo "descentradas", “deslocadas" ou "fragmentadas". Em suas palavras:

Um tipo diferente de mudança estrutural está transformando as sociedades modernas no final do século XX. Isso está fragmentando as paisagens culturais de classe, de gênero, sexualidade, etnia, raça e nacionalidade, que, no passado, nos tinham fornecido sólidas localizações como indivíduos sociais. Estas transformações estão também mudando nossas identidades pessoais, abalando a ideia que temos de nós próprios como sujeitos integrados (HALL, 2006, p. 9).

Essa constatação feita pelo autor nos traz imediatamente ao cenário em que sobrevivem os indígenas, pois não é possível mais se pensar em uma comunidade indígena integrada, dentro dos padrões culturais de sua etnia, tendo em vista a forte e esmagadora presença da cultura do não índio em terras que já foram habitadas somente pelos nativos. Pensar a identidade do sujeito indígena na cidade de Dourados, pelo menos aqueles que caíram na mendicância e não conseguiram se adequar aos padrões culturais do homem 
branco, é levar em consideração este homem descentrado, fragmentado e deslocado tanto de sua cultura quanto da cultura do homem na cidade. O que Hall denomina "perda de um sentido de si” entendemos no contexto em que pesquisamos, que não é mais possível deixar as etnias indígenas à mercê da própria sorte, como tem ocorrido. O que se dá, na perspectiva do autor, é "uma crise de identidade, quando os sujeitos estão deslocados de seu lugar no mundo social e cultural quanto de si mesmos" (HALL, 2006, p. 9).

Stuart Hall (2006) apresenta-nos o conceito de sujeito pós-moderno, aquele que se mostra fragmentado, composto por mais de uma identidade, e isso está relacionado diretamente com questões estruturais e institucionais. Em suas palavras: "o próprio processo de identificação, através do qual projetamo-nos em nossas identidades culturais tornou-se mais provisório, variável e problemático" (2006, p. 12). Para ele, a identidade é definida historicamente, não biologicamente. Hall entende que as identidades são deslocadas porque o sujeito é interpelado e representado pelos sistemas culturais nos quais estão inseridos. Para Hall (2006, p. 13),

à medida em que os sistemas de significação e representação cultural se multiplicam, somos confrontados por uma multiplicidade desconcertante e cambiante de identidades possíveis, com cada uma das quais poderíamos nos identificar - ao menos temporariamente.

Em se tratando do sujeito indígena, essa ruptura entre o sujeito que vive na aldeia e que está também submergido na relação com o não indígena na cidade não ocorre de modo pacífico e confortante, é sempre um desafio sua entrada nessa cultura que não lhe pertence. Percebemos este deslocamento na Universidade, quando ele busca o conhecimento e frequenta a sala de aula com outros alunos. Há um modo de se inserir nesse ambiente nada confortável para ele, pois não domina a língua portuguesa com a fluência esperada no meio acadêmico e o choque cultural é algo que provoca constrangimento e subserviência em muitos casos. Percebemos que o indígena busca constituir uma nova identidade a partir dos estudos e da relação com o outro, pois há um interesse em se adequar a este outro modo de vida, a esta outra cultura. O indígena é este sujeito deslocado, fragmentado, afetado pela instituição e modos de vida da cultura não indígena.

Tendo em vista a coerente noção de identidade proposta pelo autor, vale mencionar que para o sociólogo "a identidade é algo formado, ao longo do tempo, através de processos inconscientes, e não algo inato, existente na consciência no momento do nascimento. Existe sempre algo 'imaginário' ou fantasiado sobre sua unidade” (HALL, 2006, p. 38). A 
identidade, para ele, não é algo completo, mas está sempre em formação. O sujeito vai se constituir na relação com o outro no curso da história e as representações imaginárias/simbólicas fazem parte dessa formação identitária.

O que é bastante preocupante em relação às representações simbólicas quanto à identidade do sujeito indígena é que na relação com o não indígena fora da aldeia perpassa um conturbado relacionamento corroborado pelos estereótipos que se perpetuam do que seja um homem ou uma mulher indígena. Os estereótipos são criados justamente pela diferença cultural entre dois povos: o nativo "colonizado" e o não indígena. O perigo dessa relação é que o indígena vai se sentindo frustrado e criando um imaginário de inferioridade e incapacidade quando encontra dificuldades, como diplomar-se em um curso superior ou conseguir um bom emprego. Na tentativa de se adaptar a essa nova cultura capitalista e globalizada do homem branco, há uma corrida desigual entre o indígena e o não indígena; é de se pensar que não haja nada pior do que um sujeito não acreditar em si mesmo e ter toda uma estrutura corroborando para que se crie um imaginário de impotência e incapacidade.

De acordo com Stuart Hall, "as culturas nacionais são atravessadas por profundas divisões e diferenças internas" (2006, p. 62). Em sua perspectiva, uma unidade cultural só existe a partir do simbólico, ou seja, há um esforço de uma Nação para construir um imaginário do que seja uma nação britânica, por exemplo. Hall também compreende que a noção de etnia como "forma fundacional" não passa de um mito. Em suas palavras: "A Europa ocidental não tem qualquer nação que seja composta de apenas um único povo, uma única cultura ou etnia. As nações modernas são todos híbridos culturais” (2006, p. 62).

Em se tratando de Brasil, país em que se situa o objeto dessa pesquisa, entendemos que embora nos compreendamos como sujeitos brasileiros, homens e mulheres de uma só nação, é preciso considerar o poder do simbólico nesta noção, pois brasileiros sofreram processo de colonização europeia, mas também forte presença dos africanos e convívio com diferentes etnias indígenas em todo o país. Desse modo, podemos afirmar que somos um pouco negro, um pouco indígena, um pouco europeu. Novamente, dialogamos com Hall, quando ele diz que "quando vamos discutir se as identidades nacionais estão sendo deslocadas, devemos ter em mente a forma pela qual as culturas nacionais contribuem para 'costurar' as diferenças numa única identidade” (2006, p. 65).

Ao retomarmos o texto $\mathrm{B}$, em que a FUNAI se mostra empenhada em retirar as crianças indígenas do lar para adoção e devolvê-las para a aldeia, justificando a necessidade de uma manutenção de Identidade, essa justificativa se mostra fragilizada considerando todas 
as condições histórico-sociais nas quais o povo indígena está submerso. Esse posicionamento da FUNAI nos leva a dialogar com Kathryn Woodwand, quando a estudiosa diz:

As mudanças e transformações globais nas estruturas políticas e econômicas no mundo contemporâneo colocam em relevo as questões de identidade e as lutas pela afirmação e manutenção das identidades nacionais e étnicas. Mesmo que o passado que as identidades atuais reconstroem seja, sempre apenas imaginado, ele proporciona alguma certeza em um clima que é de mudança, fluidez e crescente incerteza (WOODWARD, 2014, p. 25).

Considerando as condições das crianças que se encontram no lar para adoção, portanto, em condição de abandono pelos pais, convivendo com outras crianças, funcionários do lar, que as acolhem, não é possível mais pensar em uma identidade cultural homogênea, a não ser no plano do imaginário, tal como ressalta Woodward. A autora enfatiza que "uma determinada identidade pode ser buscada, legitimada por referência a um suposto e autêntico passado-possivelmente um passado glorioso, mas, de qualquer forma, um passado que parece 'real', que poderia validar a identidade que reivindicamos" (WOODWARD, 2014, p. 28).

Nas condições que aqui analisamos, ao dizer que busca preservar a identidade cultural da criança indígena, talvez a FUNAI, na posição que ocupa na sociedade, cujo papel é atender as demandas das etnias indígenas do Brasil, tenha em vista o imaginário de um passado em que a comunidade indígena não exista nas condições em que estão submersas na atualidade. Reivindicar esta identidade cultural é negar a uma criança que se encontra em situação de abandono o direito de conviver com uma família que possa de fato atender suas necessidades. A partir do que diz Pierre Bourdieu, Woodward (2014, p.30) compreende que "os indivíduos vivem no interior de um grande número de diferentes instituições, que constituem os campos sociais, tais como as famílias, os grupos de colegas, as instituições educacionais, os grupos de trabalho ou partidos políticos".

\section{Aspectos discursivos: problematizando Subjetividade/Identidade}

Em $A$ arqueologia do Saber, Michel Foucault entende que

as diversas modalidades de enunciação, em lugar de remeterem à síntese ou à função unificante de um sujeito, manifestam sua dispersão: nos diversos status, nos diversos lugares, nas diversas posições que pode ocupar ou receber quando exerce um discurso, na descontinuidade dos planos de onde fala (2002, p. 61). 
Para Foucault (2002, p. 62), “o discurso é um conjunto em que podem ser determinadas a dispersão do sujeito e sua descontinuidade em relação a si mesmo". O filósofo não aborda conceitos de identidade diretamente, mas chama a atenção para questões relacionadas à dispersão do sujeito a partir das diversas posições que pode ocupar na sociedade. Nesse sentido, entendemos haver um diálogo entre os conceitos de Identidade propostos por Hall e Woodward no sentido de que pensar o sujeito homogêneo ou uma identidade fixa é falacioso.

No âmbito das relações sociais, o homem ocupa diversas posições e se torna sujeito que se constitui a partir das relações institucionais. De acordo com Fernandes (2012, p. 74):

É no social que se definem as posições-sujeito, não fixas, marcadas por mutabilidade e análise de discursos deve fazer aparecer esses elementos e explicitar suas formações e transformações históricas, e também suas implicações e/ou determinações na produção da subjetividade.

Para o autor, é preciso considerar o sujeito não como algo fixo e acabado, mas construído pelos deslocamentos, movências e transformações como produção de subjetividade. A subjetividade, de acordo com Fernandes (2012, p. 76), é "vista da exterioridade, apresenta-se como uma construção histórica sob determinadas condições e se dá na relação com o discurso". Na perspectiva discursiva de base foucaultiana, Fernandes compreende que o "sujeito é produzido nas relações discursivas" (2012, p. 76).

A partir dessa perspectiva discursiva entendemos que a subjetividade é constituída pelo exterior, pelas posições que o sujeito ocupa, nas relações de poder sob às quais se encontra submerso e não se trata de uma relação do sujeito consigo mesmo. Nesse sentido, indagamo-nos quanto às relações de força e de poder que constituem o sujeito-indígena sobrevivente na cidade de Dourados.

Para Fernandes (2012, p. 77), na fase foucaultiana, denominada "ética e estética da existência, Foucault focaliza o cuidado de si” e, de acordo com o autor, o sujeito se reconhece sob determinações históricas e sociais e é constituído na relação com a exterioridade. Se compreendermos que o outro, ou seja, a exterioridade atua na construção da subjetividade, a mídia acaba por reforçar o estereótipo de sujeito-indígena como criminosos, drogados, desajustados no meio social. Isso pode ser corroborado nas seguintes sequências discursivas que denominamos A3 e A4: "indígenas relatam medo porque geralmente os pais indígenas que abandonam são os mesmos que ameaçam e tentam raptar as crianças"; "os pais são dependentes de álcool e outras drogas". 
Os jornais locais da cidade de Dourados dificilmente divulgam matérias que mostrem as causas dos problemas sociais na região. Imediatistas e na busca por notícias que promovam impacto e ibope, divulgam aquilo que promove o interesse popular: violência e tragédias. $\mathrm{O}$ invisível se torna visível quando o assunto é assassinato, estupro, prisões, drogas etc. Ao expor diariamente notícias dessa natureza, a mídia ressalta e reforça aquilo que já está instituído na sociedade de modo geral, que o indígena é sujo, violento e criminoso.

As definições do que seja um sujeito indígena se dão pelo exterior e a verbalização desses discursos vai fixando valores e criando "verdades" estigmatizadas e estereotipadas. Nossas reflexões dialogam com Moreira e Guerra (2018, p. 404), pois, para as autoras, "a identidade de um sujeito constitui-se por meio de força de circulação de verdades, relações de poder advindas dos ecos de uma memória discursiva e de técnicas de persuasão que perpassam e constituem o indivíduo". No texto B, enunciado B3, há um tom de denúncia no que diz respeito à maneira como, segundo a FUNAI, as crianças são tratadas no lar. Segundo essa instituição, há um descuido dos profissionais que atuam no lar "no sentido de verbalizarem impressões preconceituosas acerca dos povos indígenas, principalmente sobre o que é noticiado na imprensa". Vejamos o que Woodward nos diz acerca do preconceito.

De acordo com Woodward (2014, p. 40), a identidade é marcada pela diferença, em suas palavras "a marcação da diferença é crucial no processo de construção das posições de identidade. A diferença é reproduzida por meio de sistemas simbólicos”. O preconceito que leva à criação de estereótipos é marcado por essas diferenças, tal como Katryn Woodward compreende o processo de construção identitária. É justamente a diferença de costumes que nessa ótica entendemos o povo indígena. Seus costumes, suas crenças, sua língua materna são diferentes em relação ao não indígena; por não compreender essas diferenças, muitas vezes, o povo indígena sofre discriminação e preconceito.

De acordo com Woodward (2014, p. 40), “as identidades são fabricadas por meio da marcação da diferença. Essa marcação da diferença ocorre tanto por meio de sistemas simbólicos de representação quanto por meio de formas de exclusão". $\mathrm{Na}$ sociedade capitalista, globalizada em que vivemos no século XXI, ser um homem integrado e bemsucedido condiz com seus bens de consumo, ter casa própria, carro, poder viajar, dominar um idioma estrangeiro, ter um bom trabalho. O indígena que está submerso nessa sociedade também acaba por almejar esses mesmos bens, no entanto, muitos vivem nas aldeias, algumas em situações bastante precárias, localizadas à margem dos centros ou dos bairros das cidades, alguns deles possuem animais com charretes e/ou bicicletas como veículo de locomoção, apresentam dificuldade para se comunicar em língua portuguesa, pois algumas etnias 
preservam a língua materna, tal como o povo Guarani. A falta de compreensão dessas diferenças é que é responsável pelos dizeres recheados de preconceito que se dão no âmbito tanto social quanto midiático.

Ao defender o posicionamento de que a identidade é constituída a partir da diferença e, portanto, na relação com o outro, Woodward compreende que

a diferença pode ser construída negativamente - por meio da exclusão ou da marginalização daquelas pessoas que são definidas como "outros" ou forasteiros. Por outro lado, ela pode ser celebrada como fonte de diversidade, heterogeneidade e hibridismo, sendo vista como enriquecedora (2014, p. 50).

Problematizando nosso objeto de análise, voltemo-nos ao enunciado A2: "a maior dificuldade para não indígenas adotarem indígenas vinha de restrições estipuladas por órgãos como a Fundação Nacional do Índio (FUNAI), para evitar que perdessem a identidade cultural". No entendimento da FUNAI, a criança indígena deve permanecer na aldeia junto a sua comunidade, preservando sua identidade. Nos dizeres de Woodward, a identidade e, portanto, a diferença podem ser encaradas como excludentes ou enriquecedoras. No nosso entendimento, uma criança indígena que for adotada por uma família não indígena irá conviver com diferentes costumes, hábitos e isso pode ser enriquecedor e não significa negar sua etnia. Preservar uma identidade cultural no sentido que a FUNAI compreende só ressalta e fortalece a exclusão. Pensar uma comunidade híbrida, heterogênea e fazer parte dela deveria ser uma condição inerente a um país tão miscigenado como é o Brasil.

\section{Consideração Finais}

O processo de objetivação/subjetivação se dá no curso da história. A Identidade, para Silva (2014), está sujeita a vetores de força, a relações de poder e se dá em um campo hierarquizado, de lutas, de resistências, num campo de disputas.

As questões indígenas que se dão na região do Mato Grosso do Sul, Dourados, são bastante complexas e não se esgotam com este artigo. Procuramos trazer à baila apenas um recorte temático no que diz respeito à problematização envolvendo processo de adoção de crianças indígenas na cidade de Dourados e região, considerando que as instituições divergem quanto aos encaminhamentos que devem dar quando o assunto é disponibilizar crianças indígenas no cadastro nacional para adoção. Procuramos, neste recorte temático, refletir e 
problematizar tal contradição, e como não poderia deixar de ser, acabamos por dialogar com autores que entendem a Identidade a partir da diferença e questões sociais e culturais, tais como reverberam os estudiosos da Cultura, e também promovemos uma interlocução com teóricos que entendem a subjetividade a partir das condições histórico-sociais.

\section{Referências}

BORGES, Águeda Aparecida da Cruz. Da aldeia para a cidade: processos de identificação/subjetivação do índio xavante na cidade de Barra do Garças/MT, alteridade irredutível? 2018. 215f. Tese (Doutorado em Linguística), Instituto de Estudos de Linguagem, Universidade Estadual de Campinas, Campinas, 2013.

BORGES, Águeda Aparecida da Cruz. Da aldeia para a cidade: processos de identificação/subjetivação e resistência indígena. Cuiabá: EdUFMT, 2018.

FERNANDES, Cleudemar Alves. Discurso e Sujeito em Michel Foucault. São Paulo: Intermeios, 2012.

FOUCAULT, Michel. A ordem do discurso. 3 ed. Tradução Laura Fraga de Almeida Sampaio. São Paulo: Loyola, 1996.

FOUCAULT, Michel. A arqueologia do saber. 6 ed. Tradução Luiz Felipe Baeta Neves. Rio de Janeiro: Forense Universitária, 2002.

FOUCAULT, Michel. A hermenêutica do sujeito (curso dado no collège de France 19811982). 2 ed. Tradução Márcio Alves da Fonseca e Salma Tannus Muchail. São Paulo: Martins Fontes, 2006.

FUNAI. Política Indigenista. Disponível em: <http://www.funai.gov.br/index.php/quemsomos> Acesso em: 4 maio 2019.

MOREIRA, Icléia Caires; GUERRA, Vânia Maria Lescano. Um olhar discursivo sobre o processo de subjetivação do indígena em dispositivo didático. Rua, v. 24, n. 2, p. 395-412, nov. 2018.2 Disponível em: <https://periodicos.sbu.unicamp.br/ojs/index.php/rua/article/view/8653945>. Acesso em: 20 maio 2019. DOI: https://doi.org/10.20396/rua.v24i2.8653945

ORLANDI, Eni Puccinelli. Terra à vista. Discurso do confronto: velho e novo mundo. 2 ed. Campinas: Editora da UNICAMP, 2008.

ORLANDI, Eni Puccinelli. Análise de discurso: princípios e procedimentos. 4 ed. Campinas: Pontes, 2002.

HALL, Stuart. A Identidade cultural na pós-modernidade. 11 ed. Tradução Tomaz Tadeu da Silva e Guacira Lopes Couto. Rio de Janeiro: Lamparina, 2006. 
SILVA, Tomaz Tadeu; HALL, Stuart; WOODWARD, Katryn. Identidade e Diferença: a perspectiva dos estudos culturais. 15 ed. Petrópolis: Vozes, 2014.

PÊCHEUX, Michel. Semântica e discurso: uma crítica à afirmação do óbvio. 3 ed. Tradução Eni P. Orlandi. Campinas: Editora da Unicamp, 1997.

TORCHI, Gicelma da Fonseca Chacarosqui; LIMBERTI, Rita de Cássia Pacheco; MELO, Sílvia Mara de. Nas tramas do Discurso: aspectos Culturais e Ideológicos. Florianópolis: Insular, 2017.

WOODWARD, Katryn. Identidade e Diferença: uma introdução teórica e conceitual. In: SILVA, T. T.; HALL, S.; WOODWARD, K. Identidade e Diferença: a perspectiva dos estudos culturais. 15 ed. Petrópolis: Vozes, 2014.

Recebido em: 22 de maio de 2021

Aceito em: 20 de setembro de 2021 